\title{
A Relevance Theoretical Reading of Wole Soyinka's The Lion and the Jewel
}

\author{
Adaoma Igwedibia* \\ Department of English and Literary Studies, University of Nigeria, Nigeria \\ Corresponding Author: Adaoma Igwedibia, E-mail: adaoma.igwedibia@unn.edu.ng
}

\section{ARTICLE INFO}

\section{Article history}

Received: March 19, 2018

Accepted: May 25, 2018

Published: September 01, 2018

Volume: 7 Issue: 5

Advance access: July 2018

Conflicts of interest: None

Funding: None

\begin{abstract}
There would be no communication, business transactions or propagation of culture and beliefs but for the existence of language. Language is the most important tool for communication. The utterances human beings make are being governed by situation, event or occurrences at a given point in time. Meaning is derived based on the context in which the utterances occur and this is the essence of pragmatics. This paper seeks to carry out an analysis of some extracts in Wole Soyinka's The Lion and the Jewel using the relevance theory in pragmatics. Relevance theory as propounded by Sperber and Wilson (1986) claims to provide a logical and cognitive account of relevance in communication. The theory tends to explain communication that takes into account implicit inference. It argues that the hearer or reader will search for meaning in any given communication situation and having found meaning that fits his expectation of relevance meaning, he will stop processing. This is in effect is what this paper attempts to explore using The Lion and the Jewel. Speakers and writers often mean much more than they say or write and expect their hearers or readers to understand them. They will generally assume that some aspects of meanings that are not expressed in words are deducible from the context. This assumption is based on their shared environment, values, social conventions, words or grammatical structures.
\end{abstract}

Key words: Language, Pragmatics, Context, Utterance, Relevance Theory, Communication, Inference

\section{INTRODUCTION}

Language is one of the most fundamental aspects of human behavior and the development of language into a refined instrument of expression and communication is without doubt the man's greatest achievements. The rapid development of all branches of language studies according to Nwaozuzu (2008, p.1) has led to a widespread and growing interest in the activities of linguists, who at each stage have sought to provide solutions to new problems. Even though certain areas of language studies have become so familiar that they have almost been taken for granted, there are others that have not yet been given adequate attention in some languages especially those that are still new in the history of linguistic analysis. One of such areas is pragmatics.

Pragmatics, a word ultimately derived from an ancient Greek verb meaning "to do" is defined as the study of language in use. In phonology, morphology and syntax the focus is on the study of formal elements of linguistic structures and the linguistic system. These structures and the linguistic system as a whole are studied in separation from possible contexts of use. The communicative context and language use do not play a central role even in semantics, the linguistic sub-discipline devoted to the study of meaning. What is in focus in semantics is the propositional content (that is the semantic potential of a clause or sentence), not its actual meaning in a specific context of use. In other words, we can study phonology, morphology, syntax and semantics without really paying any systematic attention to the intentions of speakers or writers, the context of the utterance or text, or the effects they produce on listeners and readers. This is different in pragmatics. Here the focus is on the utterance in its specific communicative context, and on its relation to the intentions of the speaker and the responses of the listener. Utterances usually do not occur in isolation but as parts of larger amounts of language in use - conversations, radio interviews, news broadcasts, letters, e-mails messages, newspaper articles, chapters in books, poems, and many more. Such larger units, especially when written, have traditionally been referred to as texts.

This work is built on the relevance theory in pragmatics. This is because relevance theory is a cognitive approach to human communication based on the premise that human cognition is geared towards maximization of relevance in the information they process in the course of a conversational interaction. This is the first principle of relevance. An utterance is relevant when it connects to available contextual assumptions i.e. when it relates to the context of conversation. Here it is said to yield a Positive Cognitive Effect. Maximization of relevance implies getting this cognitive effect 
of an utterance at the least processing effort possible by the hearer. However, the second principle of relevance provides the speaker's utterance has to be made relevant enough to be worth the hearer's attention. Hence, every act of ostensive communication (e.g. an utterance) communicates a presumption of its own optimal relevance. What makes an utterance relevant are thus, two basic things: the cognitive effect it yields and the processing effort required to recover the effect; i.e. effect and effort. The communicative effect of an utterance in other words, is the explicature, defined simply in Relevance Theory as "an explicitly communicated assumption" (Sperber and Wilson, 1986, p. 182).

The drama text under the present study is written by an African writer Wole Soyinka. The Lion and the Jewel, written in London is the first major play to draw on traditional Yoruba poetry, music, and dance to tell a Nigerian story in English. The play enables Nigerian drama to becomepart of world theatre. The play focuses on several conflicts that Soyinka presents but does not attempt to resolve. Lakunle and Baroka embody the contrary urges toward modernity and tradition. They personify the two sides of the major social and political issue in Africa society. Several works have been done by scholars on the study of Wole Soyinka's The Lion and the Jewel, especially through literary/critical analysis. The Relevance Theory as a pragmatic theory of utterance interpretation is applicable to all dialogic or conversational interactions. However, it has not been applied to the analysis of the text, The Lion and Jewel which emphasizes the theme of corrupted African culture and how the youth should embrace the original African culture. Hence, the gap this study is set to fill.

The objective of this study is to examine how the intended meaning of the speaker is communicated to the hearer and how the hearer interprets it based on inputs provided by the speaker and contextual evidence. This study is also to examine how explicatures are recovered by the hearers. Explicature is a pragmatic term coined by Sperber and Wilson to describe the explicit intentions of a speaker contained in his or her encoding of a message which the hearer however needs to interpret or recover via some processes of inference.

\section{Scope of the Study}

This study will be limited to the identification and analysis of conversations in The Lion and Jewel. Some conversations found in the chosen text will constitute the body of data for this research work. This work will not examine conversations outside the chosen text. Relevance Theory will be used in the course of this study.

\section{Significance of the Study}

The relevance theoretic study of The Lion and the Jewel reveals the processes of recovering explicatures from utterances in the texts. These processes facilitate access to the thematic foci, character exposition and setting of the text. Since the text is preoccupied by the corrupted African culture and how the youth should embrace the original African culture, the study is of great importance to the general public as it illuminates how these issues are influenced by language. The study is also beneficial to linguists in demonstrating the applicability of Relevance Theory to the selected text.

\section{LITERATURE REVIEW}

\section{Literary Studies on the Lion and the Jewel}

Moawad (2016) embarked on the study, "A study of Wole Soyinka's Play The Lion and the Jewel in the Light of Cultures in Conflict." The researcher finds in this study that Soyinka manages to reflect to the world that the dominated culture is the traditional one besides reflecting the view of the world, beliefs, and condition of cultures.Kumar (2011) carried out a study on "Yoruba Tradition and Culture in Wole Soyinka's The Lion and the Jewel." The researcher argues that the playwright reiterates upon the idea that the West has not made any deep impact on African culture and the tradition in the society is typical with all its merits and demerits. The play exemplifies a voracity that amidst the search for requirements, conflicts and confrontation, man must channelize the stream of his mental faculty unfettered by the tyranny of customs and beliefs, as worthless as desert, preserving the mental resources for the functioning modes of national mechanism with the knowledge unhampered by the constraints of ideologies.

Motsa (2007), wrote an article entitled, "Music and Dramatic Performance in Wole Soyinka's Plays." This researcher in this article demonstrates how the song genre is used in Soyinka's plays alongside other dramatic features such as ritual, drumming, chants, dance and mime for effective theme delivery. From this study, the researcher discovers that the play, The Lion and the Jewel, has enjoyed the status of a set-book for literature examinations in Southern Africa.

\section{THEORETICAL FRAMEWORK/METHODOLOGY}

\section{Relevance Theory}

Relevance theory is, among other things, an attempt to ground models of human communication squarely in cognitive psychology. It is a pattern of linguistic engagement that tries to work out in detail, Grice's central claim that an essential feature of most human communication, both verbal and non-verbal is the expression and recognition of intentions (Grice 1989).

It goes without saying it that no theory exists in a vacuum, consequently, relevance theory is basically a modification or improvement on other theories of communication that predate it. The theorists, Dan Sperber and Deirdre Wilson have significantly embarked on this theoretical journey by highlighting the merits of the preceding theories and their demerits which evidently create the research slot for their theoretical enterprise: communication, relevance and cognition.

The theorists, first, took a stand with the inferential model of communication as against the code-model. From Aristotle through to modern semiotics, all theories of communication were based on a single model - the code-model. The 
Code-model teaches that communication is achieved by encoding and decoding message. But for the inferential model, communication is achieved by producing and interpreting evidence.

\section{Sperber and Wilson's Argument against the Code-model}

The theorists substantiate their preference for inferential model as against the code model with the following salient observations:

1. Human languages such as Swahili or English are codes

2. The codes associate thought to sounds

3. The code model pair phonetic and semantic representation of sentences while most sentences can be used to convey an infinite number of sentences, the semantic representation of sentences cannot be regarded as corresponding very closely to thoughts.

4. The code model being paired with semantic representation of sentences can take no account of such linguistic properties such as the time and place of utterance, the identity of the speaker, the speaker's intention etc.

5. The code model commits us to the mutual knowledge hypothesis which, in actuality, does not exist.

6. They argue that communication is successful not when hearers recognize the linguistic meaning of the utterance but when they infer the speaker's meaning from it. For instance, when hearers realize that the speaker has misused a word, or made a slip, they generally discount the wrong meaning. The meaning they discount is wrong because they provide misleading evidence about the speaker's intention.

7. They further argue that to substantiate the code-model of verbal communication, it has to be shown that every case of reference assignment can be dealt with by rules which automatically integrate properties of the context with semantic properties of the utterance - and such rules can be better described as far cry.

Sperber and Wilson also capture the flaws in Paul Grice's approach as contained in an article he published in 1957. Grice has made the following postulation: S meant something by $\mathrm{X}$ and $\mathrm{S}$ intends $\mathrm{X}$ to produce effect/response in $\mathrm{A}$ by A's recognition of S's intention (to inform).

Sperber and Wilson argue that intentions to inform are largely achieved by being made recognizable. They substantiate the above claim with an example on Mary's intention to inform Peter of her coarse voice which is fulfilled by the virtue of the coarseness of her voice whether Peter recognizes her intentions or not. (Sperber and Wilson 1995:22).

Context: A psychological construct, a subset of the hearer's assumption of the world. It is the assumption, rather than the actual state of the world that affect the interpretation of the actual state of the world.To understand Sperber and Wilson's relevance theory, one should have an unambiguous understanding of the many concepts raised by the theorists which serve as the structural plank upon which relevance theory is anchored. Within the current climate of our interrogation of relevance theory, we shall therefore, take delight in the definition and explanation of relevant concepts to relevance theory.

\section{Cognitive Environment}

A cognitive environment of an individual is a set of facts that are manifest to him. An individual's total cognitive environment is the set of all the facts that he can perceive or infer: all the facts that are manifest to him. His total cognitive environment is a function of his physical environment and his cognitive abilities.

Manifest: A fact is manifest to an individual at a given time if and only if he is capable at that time of representing it mentally and accepting its representation as true or probably true. To be manifest is to be perceptible or inferable. Any assumption that an individual is capable of constructing as true or probably true is manifest to him.

\section{Levels of Manifestation}

When a phenomenon is noticed, some assumptions about it are standardly more accessible than the others. In an environment where the door bell has just rung, it will be strongly manifest that there is someone at the door, less strongly that whoever is at the door is tall enough to reach the bell and less strongly still that the bell has not been stolen.

However, we wish to state that this levels of manifestation could be altered by old information. One is a product of what is manifest in his cognitive environment.

There could be many assumptions manifest to an individual; the choice to process those assumptions that are most relevant to him captures the nucleus of relevance theory.

\section{Specific Cognitive Abilities}

All human beings are constrained by their species - specific cognitive abilities in developing their representations of the world. For instance, two people witnessing the same event even a salient and highly memorable one like car accident, may construct dramatically different accounts/representations of it; disagreeing not just in their interpretation of it but in their memory of the basic physical facts. This according to Sperber and Wilson is because individuals tend to be highly idiosyncratic. It is clear that individuals of the same linguistic community converge on the same language, but the same is not true about their perceptions of the world.

\section{Mutual Cognitive Environment}

Any shared cognitive environment in which it is manifest which people share it is a mutual cognitive environment. For instance, every freemason has access to a number of secret assumptions which includes the assumption that all Freemasons have access to the same secret assumptions. This means that all Freemasons share a cognitive environment which contains the assumption that all Freemasons share this environment.

\section{Ostensive Behaviour or Ostension}

Ostensionis behaviour which makes manifest an intention to make something manifest. For instance, if Peter leans back and Mary notices certain phenomena, the things that are made manifest to Mary are the phenomena in sight, if part 
of the phenomena is what she has seen, Sperber and Wilson call it old information, if the information is not relevant to her, it will be a waste of mental effort to process it; if any of the phenomenon is new, it becomes new information; part of the things made manifest to Mary is Peter's learning back in order to attract her attention to a particular phenomenon. Then Peter's behaviour has made it manifest to Mary that he intends to make a particular assumption manifestto her. This, Sperber and Wilson designate as Ostension.

Just as an assertion comes with a tacit guarantee of truth, ostension come with a tacit guarantee of relevance.

\section{Principle of Relevance}

This implies that an act of ostension carries the guarantee of relevance and, as a result, provides evidence of one's thought. Ostensives, we argue, have the ability to vibrate the cord of search in individuals especially as it is associated with relevance.

Sometimes, part of the basic information will not be manifest at all unless the intension behind the ostension is taken into account. Example given by Sperber and Wilson is an old man looking ostensively at the sky and few tiny clouds which a girl traveling in a foreign country has noticed but had paid no further attention to it. If she accepts his guarantee of relevance, she has to find out what makes him think that the presence of the cloud would be relevant to her. Sperber and Wilson argue further that the attention given to the ostension will make the girl realize that it was about to rain. Here, we tend to disagree with Sperber and Wilson given that we can't process how the girl would suddenly make such association if she has never ever related tiny clouds with rain.

\section{Explicit and Implicit Communication Model}

Sperber and Wilson talk about explicit and implicit communication method. In their words: pragmatists hold the view that what is communicated by an utterance is a speaker's meaning which in the case of an assertion is a set of assumptions. One of these assumptions is explicity expressed; the other (if any) is implicitly conveyed or implicated. The difference between the two contents of utterance is that the explicitcontent is decoded while the implicatures are inferred. What is implicitly conveyed by an utterance is generally much vaguer that what is explicitly conveyed, and when the implicit import of an utterance is explicitlyspelt out, it tends to be distorted by the elimination of the often intentional vagueness. The distortion, they argue, is even greater in metaphor and other figures of speech as their poetic effect are generally destroyed. The above situation captured by Sperber and Wilson has been designated in extant literature by Aristotle as deadmetaphor.

Proposition: A proposition is the content of a sentence that affirms or denies something and is capable of being true or false.

Impression: An impression might be better described as a noticeable change in one's cognitive environment; a change resulting from relatively small alterations in the manifestness of many assumptions rather than that a single assumption or few assumptions have all of a sudden become very manifest.

Inference: This is the process by which an assumption is accepted as true or probably true on the strength of the truth or probable truth of other assumptions.

\section{Relevance Information}

Relevance information is one that modifies and improves on overall representation of the world. The representation of assumption is never static; it fluctuates. The strength of an assumption may be established but sometimes varies as a by-product of other processes. A good example is the expression of passion for football by someone who watches football but some other time declines to do so, thereby leading to weak assumption about the hitherto strong assumption that he is a football lover.

The propositional form arrived at by completing the logical form of an uttered sentence can be integrated by a standard procedure into an assumption about what the speaker said.

E.g.

ai $\partial \mathrm{m} \partial$ stju: dont $\quad$ - utterance

I am a student - logical form

Mary is a student - propositional form

Mary says that - assumption schema

Mary says that Justice is a student - assumption.

Assumption is formed thus:

If $A$ then $B$

If not $\mathrm{A}$ then not $\mathrm{B}$

If $\mathrm{A}$ then $\mathrm{A}$ because of $\mathrm{B}$.

This could be captured as follows:

If I eat then I am human

If I do not eat then I am not human

If I do not eat, I do not eat because I am not human

The relevance of new information to an individual is to be assessed in terms of the improvement it brings to his representation of the world. The addition of new information which merely duplicates old information does not count as an improvement; nor does the addition of new information which is entirely unrelated to old information (especially when it does not share the same [cognitive] context with the old information).

\section{How Weak Contradicting Assumptions are Erased from the Memory}

When two assumptions are found to contradict each other, their strengths are compared and if one is found to be stronger than the other, the deductive device automatically erases the weaker assumption. When an assumption is erased, the device also erases any assumption which analytically implies it. This procedure applies recursively until no more erasure can take place.

\section{Contextual Effect}

This could occur in the form of an erasure of some assumptions from the context, a modification of the strength of some 
assumptions in the context, or the derivation of contextual implications.

\section{Relevance}

Having contextual effect is a necessary condition for relevance, and other things being equal, the greater the contextual effect the greater the relevance

The idea of relevance, cognitively speaking, is a cost/ benefit analysis whereby the cost of processing is weighted against the possible cognitive benefit. The assessment of relevance, like the assessment of productivity, is a matter of balancing output against input; as in, contextual effect against processing effort.

\section{Therefore}

An assumption with greater contextual effect is more relevant, and an assumption requiring smaller processing effort is more relevant.

If the benefits of achieving contextual effect were never enough to offset the cost of the processing effort needed to implement it, then a positive degree of relevance could never be achieved. Thinking would not worth the effort.

\section{Assumption Could be Irrelevant in a Context in the Following Ways}

1. When it contributes a new information but this information does not connect up with any information present in the context.

Eg: Mr. A: Noun is a part of speech in English.

Mr. B: Nigeria lost to South Africa

2. When the assumption is already present in the context and its strength is unaffected by the new information.

Eg: Mr. A: There are about seven grammatical functions of noun in English.

Mr. B: There are seven parts of speech in English.

3. When the assumption is too weak, inconsistent with the context and amounts to waste of mental effort to process it.

Eg: I am delivering a paper on relevance theory

\section{How Context is Chosen}

The context for the comprehension of an utterance consists of the assumptions expressed and implicated by preceding utterances, plus the encyclopedic entries attached to any concept used in any of these assumptions, plus the encyclopedic entries attached to any concept used in the new utterance.

Background assumption + new information $=$ context.

What determines a particular context is largely the search for relevance

The process is:

a) Determine context

b) Information takes place

c) Relevance is assessed.

The central argument of Sperber and Wilson is that the individual in a communicative event pays attention to rel- evant phenomena, and to process them so as to maximize relevance.

Worthy of note here is Wilson and Sperber's warning that people should not think that a proper semantic analysis of the English word relevance would characterize a concept of scientific psychology. Succinctly put, relevance as a technical term is restricted to relationships between utterances and interpretations.

\section{Methodology}

The source of data for this study involves a dramatic text: The Lion and the Jewel. Out of this, excerpts were drawn for analysis. The theory privileged in the analysis remains Sperber and Wilson's (1986) Relevance Theory. The method of analysis involves interpretation and explanation. The explanation gives attention to relevance theoretic terms such as Reference Assignment and Inference and the role of context in attaining them.

\section{ANALYSIS}

The play centers on three major characters-Lakunle, a school teacher, Baroka, the village chief and Sidi, the jewel of the village. The play is set in a small remote village Ilujinle.

Lakunle represents the West and modernity while Baroka represents tradition especially of the Yoruba. Both men are interested in Sidi. They compete to marry her. Lakunle who professes modernity even without really understanding it, wants to marry Sidi without paying her bride price. He tells her about his undying love for her and whenever Sidi raises up the issue of bride price he picks offence and refers to such culture as barbaric. Baroka, the sixty-two years old chief became interested in making Sidi one of his wives after seeing the beautiful face of Sidi in the Magazine that the foreign photographer who gave her a snapshot published. At last, it is the old chief Baroka that succeeds in marrying the Jewel, Sidi although in cunning way. Lakunle and Baroka embody the contrary urges towards modernity and tradition. They personify the two sides of the major social and political issue in Africa.

Discourse Context One: Sidi intends for Lakunle to give her back her pail

Lakunle; Let me take it

Sidi; No

Lakunle; Let me [seizes the pail. Some water spills on him] Sidi;This is what the stew pot said to the fire, have you no shame-at age you are licking my bottom? But she was tickled just the same.

Sidi; The school teacher is full of stories this morning, and now if the lesson is over, may I have the pail?

Lakunle; No.... (Morning)

Analysis: The italicized utterance by Lakunle is by explicature of no relevance to the discourse Context which is why Sidi gives a sarcastic reply. It however may be said to be the immediate discourse context.

Discourse Context Two: Sidi is insistent on following the bride price custom 
Sidi; But I tell you Lakunle, I must have the full bride price. Will you make me a laughing stock? Well do as you please but Sidi will not make herself a cheap bowl for the village to spit.

Lakunle; On my head let fall their scorn.

Sidi; They will say I was no virgin, that I was forced to sell my shame and marry you without a price.

Lakunle; A savage custom, barbaric, outdated, rejected, denounced, accursed, excommunicated, archaic, degrading, humiliating, unspeakable, redundant, retrogressive, remarkable, unpalatable.

Sidi; Is the bag empty? Why did you stop?

Lakunle; I own only the Shorter Companion Dictionary but Wait I have ordered the longer one-you

Sidi; Just pay the price. (Morning)

Analysis: the italicized utterances by Lakunle have no contextual effect. This is why Sidi givesa sarcastic reply to the first utterance and totally ignores the second utterance.

Discourse Context Three: Baroka intends to indicate his puzzlement at Lakunle's sneaking away upon his (Baroka's) appearance at the scene

Baroka: Akowe. Teacher wa, mistaLakunle

Lakunle; A good morning to you sir

Baroka; Guru morin, guru morn, nbh! That is all we hear from 'alakowe'. You call at hishouse hoping he sends for beer but all you get is guru morin. Will guru morin wet my throat? Well well our man of knowledge, I hope you have no query an old man today.

Lakunle: No complaints

Baroka: And we are feuding in something I have forgotten

Lakunle: Feduing sir? I see no cause at all

Baroka; Well the play was much have alive until I came; now everything stops and you were leaving us. Afterall I know the story and I came in right on cue. It makes me feel as if I was chief Baseje

Launkle; One hardly thinks the Bale will have the times for such childish nonsense

Baroka; A-ah mister Lakunle. Without these things you call nonsense, a Bale's life will be pretty dull. Well now that you say I am welcome, shall we resume your play.... (Morning)

Analysis: The italicized utterance by Baroka is of no relevance to the discourse context. It adds no knowledge to the set of pre-existent knowledge in the minds of the listeners within the discourse context.

Discourse Context Four: Sadiku intends to inform that Baroka wants to see her and take her as a wife.

Sadiku; Fortune is with me, I was going to your house to see you

Sidi; What! Oh it's you Sadiku

Sadiku; The lion sent me, he wishes to see you.

Sidi; Thank him for me. Have you seen these? Have you seen these images of me wrought by the man from the capital city? Have you felt the gloss? Smoother by far than the parrot's breast

Sadiku; I have. I saw them as soon as the city man came... Sidi, I bring a message from my lord.
Shall we draw aside a little?

Sidi: Him? Pay no more heed to that than you would a eunuch

Sadiku; Then in as few words as it takes to tell, Baroka wants you for a wife.

Launkle: what! The greedy dog! Insatiate camel of a foolish doting race. Is he at his tricks again?

Sidi; be quiet Kunle. You get so tiresome. (Noon)

Analysis; The italicized utterances are of little relevance to the discourse context. This is why for the first utterance, the listener's answer all but brushes aside the utterance and in the case of the second utterance, the discourse participants completely ignore it.

DiscourseContext Five: Sadikuinforms Baroka of Sidi's response to his proposal

Sadiku; My lord

Baroka; You have my leave to speak. What did she say?

Sadiku; She will not my lord. I did my best but she will have none of you.

Baroka: It follows a pattern-a film refusal at the start. Why will she not?

Sadiku: That is the strange part of it. She says you are much too old. If you ask me, I think she is really off her head. All this excitement of the book is too much for her.

Baroka: She say... that I am old. That I am old? Did a slight unripened girl say this of me?

Sadiku: My lord, I heard the incredible words with my ears and I thought the world was mad

Baroka;... Perhaps it is as well Sadiku

Sadiku: My lord what did you say?

Baroka; yes faithful one, I say it as well. The scorn, the laughter and the jeers would have been bitter. Had she consented and my purpose failed, I would have sunk with shame.(Noon)

Analysis: The italicized utterances by Baroka have no contextual effect within the discourse context. The brain of the listener tries to process them and determine their relevance within the discourse context and comes up blank. They are totally unrelated to what is being discussed. For this reason, the listener replies by making utterances laced with a degree of puzzlement. These replies made by the listener indicate a need for clarification.

Discourse Context Six: Sidi intends to find out the reason behind Sadiku's jubilation

Sadiku: Oh it's you my daughter. You should have chosen a better time to scare me to death. The hour of victory is no time for any woman to die.

Sidi: Why? What battle have you won?

Sadiku: Not me alone girl, you too, every woman. Oh my daughter... that I have lived to see this day... to see him fizzle with the drabbest puff of a mis-primed "sakabula' \{resumes dance\} take warning my masters, we will scotch you in the end.

Sidi: Wait Sadiku, I cannot understand

Sadiku: You will my girl, you will. Take warning my masters....

Sidi: Sadiku are you well?

Sadiku: Ask no more questions my girl. Just join me in my victory dance. Oh Sango my lord, who of us possessed 
your lightening and ran like fire through that lion's tail... Sidi: Stop your loose ranting. You will not move from here until you make sense

Sadiku; Oh you are troublesome. Do you promise to tell no one?

Sidi: I swear it. Now tell me quickly.... (Night)

Analysis; The italicized utterances made by Sadiku have very little contextual effect within the discourse context. The brain of the listener tries to determine their relevance within the conversation and is not able to do so. For this reason, the second speaker severally seeks for clarification from the first speaker as the first speaker's utterances seem not to make sense.

\section{CONCLUSION}

Relevance theory is a psychological model of understanding the cognitive interpretation of language, as well as an inferential approach to pragmatics. It stands opposed to classical code-model which holds that information is encoded into a message, transmitted and decoded by another party or person, with another copy of the code. The code model is quite related to Michael Reddy's conduit metaphor.

The locus of Sperber and Wilson's relevance theory is that the hearer/reader will search for meaning in a given communication situation and having found meaning that fits their expectation of relevance will stop processing. Thus,
Sidi in The Lion and the Jewel picks and chooses the meanings which suit her best from Lakunle's,Baroka's and other character's speeches. Lakunle does the same while speaking with Sidi and other characters. Therefore, the application of this theory to the interpretation and analysis of Soyinka's The Lion andthe Jewel has indeed revealed the deeper meaning of this text.

\section{REFERENCES}

Kumar, D. (2011) "Yoruba Tradition and culture in Wole Soyinka's The Lion and the Jewel. "Journal ofArts, Science and Commerce, 11(3).

Moawad N.M.I. (2016) “A Study of Wole Soyinka's Play The Lion and the Jewel in the Light of Cultures in Conflict. International Journal of English and Literature, 7(12), pp. 179-188.

Motsa, Z. (2007) Music and Dramatic Performance in Wole Soyinka's Plays. Journal of Music Research in Africa, 4, pp. 178-189.

Nwaozuzu, G. I. (2008) Dialects of the Igbo Language. Nsukka: University of Nigeria Press.

Soyinka. W. (1963) The Lion and the Jewel. Oxford University Press.

Sperber. D., \& Deirdre. W. (1996) Relevance: Communication and Cognition. Second Edition. Oxford: Blackwell Publishers Ltd. 